\section{Learning points}

- nephrotic syndrome is a hypercoagulable state

- thrombotic episodes are frequent manifestations of the hypercoagulable state in nephrotic syndrome

- although less common than venous thrombosis, arterial thrombosis may be life-threatening

- normal coronary vessels may be seen in young patients with acute myocardial infarction

- a hypercoagulable state is a possible contributory factor to coronary artery thrombosis

- normal coronary angiography should prompt a search to rule out an underlying hypercoagulable state

Box 4

1 Kendall AG, Loohmann RC, Dossetor JB. Nephrotic syndrome: a hypercoagulable state. Arch Intern Med 1971;127:1021-7.

2 Llach F. Hypercoagulability, renal vein thrombosis and ther thrombotic complications of the nephrotic syndrome. Kidney Int 1985;28:429-39.

3 Fahal IH, McClelland P, Hay CRM, Bell GM. Arterial thrombosis in the nephrotic syndrome. Postgrad Med $\mathcal{f}$ 1994;70:905-9.

4 Cameron JS. Coaglation and thrombo embolic complications in the nephrotic syndrome. Adv Nephrol 1984;13:7514.

5 Bellomo R, Atkins RC. Membranous nephropathy and thromboembolism: is prophylatic anticoagulation warranted? Nephron 1993;63:249-54.

6 Kim HJ, Park CH, Kang CM, Park HC. Arterial thrombosis associated with the nephrotic syndrome - a case report and review (adult cases in English Literature). 7 Kor Med $S c i$ 1993;8:230-4. state. ${ }^{10}$ In all patients with a proven myocardial infarction and normal coronary vessels, a search should be made for any of these conditions.

\section{Final diagnosis}

Nephrotic syndrome complicated by acute anteroseptal myocardial infarction.

Keywords: nephrotic syndrome; myocardial infarction

7 Mukheriee AP, Toh BH, Chan GL, Lau KS, White JC. Vascular complications in the nephrotic syndrome: relationship to steroid therapy and accelerated thromboplastin generation. $B M \mathcal{F} 1970 ; 4: 273-6$

8 Fujimara O, Gulamhusein S. Acute myocardial infarction: thrombotic complications of nephrotic syndrome. Can $\mathcal{F}$ Cardiol 1987;3:267-9.

9 Lip G, Tean KN. Acute myocardial infarction: a rare complication of the thrombolic tendency in nephrotic syndrome. Br $\mathcal{f}$ Clin Pract 1994;48:218-20.

10 Pasternak RC, Braunwald E, Sobel BE. Acute myocardial infarction. In: Braunwald E, ed. Heart disease - a text book of cardiovascular medicine, vol 2, 4th edn. Philadelphia: WB Saunders, 1992; pp 1200-91.

\title{
A dislocated finger
}

\section{H Gerrand, P M Jarrett}

A 64-year-old man presented 12 hours after he fell onto his hand whilst intoxicated. X-Rays are shown in figure 1.

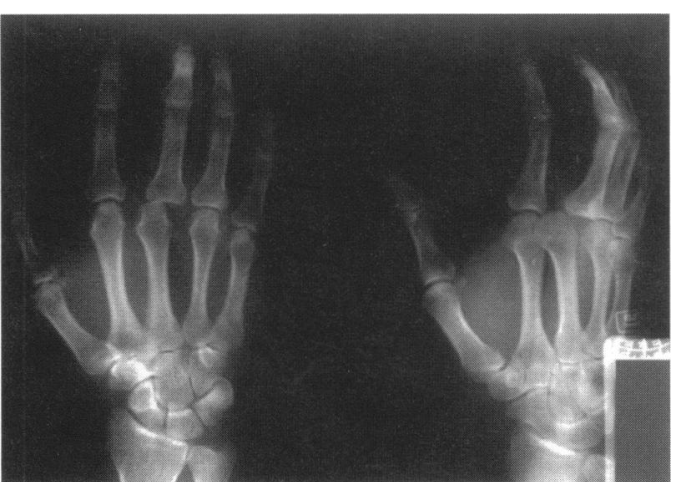

Figure $1 \mathrm{X}$-Rays of the patient's hand at presentation

\section{Questions}

1 What does the radiological appearance suggest?

2 What is the anatomy of this injury?

3 What is the correct treatment?
Department of

Orthopaedics, Western

Infirmary, Dumbarton

Road, Glasgow G11

6NT, UK

C H Gerrand

P M Jarrett 


\begin{abstract}
Answers
QUESTION 1

The X-rays show dislocation of the metacarpophalangeal joint of the right middle finger. The attitude of the proximal phalanx which lies almost parallel to the metacarpal suggests a complex dislocation.

QUESTION 2

Kaplan's description of this injury in the index finger is elegant. ${ }^{1}$ At the time of injury, the fibrocartilaginous volar plate breaks away from its weakest attachment to the volar aspect of the metacarpal neck. Further force displaces the flexor tendons to the ulnar side and the lumbrical muscle to the radial side of the metacarpal head. The volar plate becomes trapped
\end{abstract}

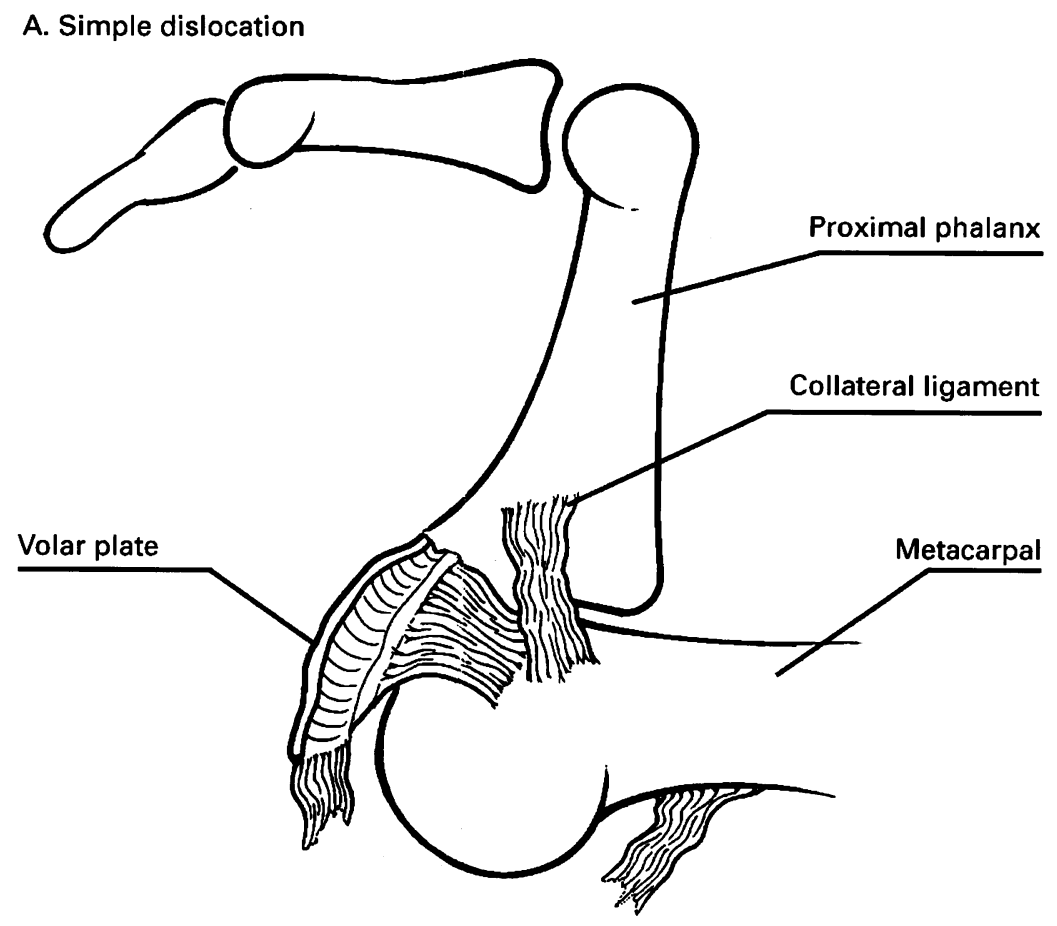

\section{B. Complex dislocation}

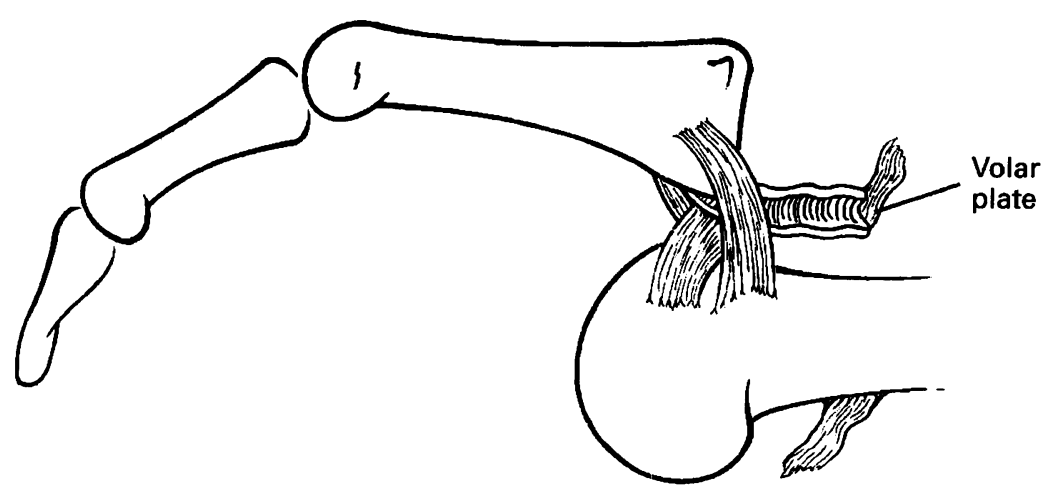

Figure 2 (A) Simple dislocation. Note the hyperextended position of the metacarpophalangeal joint. (B) Complex dislocation. The volar plate is trapped in the metacarpophalangeal joint. The proximal phalanx lies almost parallel to the metacarpal in the joint and the collateral ligaments hold the proximal phalanx in an abnormal position (figure 2). Three transverse bands of fascia have been implicated in the dislocation; the natatory ligaments which are transverse fascial fibres spanning the web spaces just beneath the skin, the superficial transverse metacarpal ligament which consists of transverse fibres of palmar fascia bridging the gaps between the longitudinal pretendinous bands, and the deep transverse metacarpal ligament which runs between the volar plates in front of the metacarpals. ${ }^{2}$ The deep transverse ligament is the most intimately involved of these as it attaches to the volar plate and traps it in the joint. The other two bands are said to trap the metacarpal head, the superficial transverse metacarpal ligament on the volar aspect and the natatory ligament on the dorsal (figure 3).

\section{QUESTION 3}

Closed reduction is successful in half of all cases. The joint is hyperextended, the articular surface of the proximal phalanx is applied firmly to the metacarpal neck and the joint is flexed. ${ }^{3}$ Attempts at closed reduction should not be prolonged.

Open reduction can be performed through a volar or a dorsal approach. The volar approach to the index finger described by Kaplan ${ }^{1}$ can be adapted to the middle finger. ${ }^{4}$ An incision is made in the thenar crease of the palm. Care is taken not to damage the neurovascular bundle which is pushed forward by the metacarpal head. The natatory ligament, the superficial transverse ligament and the deep transverse metacarpal ligaments are all divided and the volar plate removed from the joint with a blunt hook. The joint is reduced and the volar plate reattached to the base of the proximal phalanx.

In the approach described by Becton et al, ${ }^{5}$ a dorsal incision is made over the metacarpophalangeal joint, splitting the extensor tendon and joint capsule in the same line. A longitudinal incision is made in the volar plate which permits reduction of the joint after flexing the wrist to relax the flexor tendons.

Postoperatively, some authors recommend mobilisation within a week, ${ }^{26-8}$ but others splintage for up to three weeks. ${ }^{5}$

In this case, closed reduction in the Accident and Emergency department under metacarpal block was attempted unsuccessfully. Open reduction was performed through a volar incision. The digital nerve lay superficially under the skin and was preserved. Reduction was achieved after dividing the A1 pulley, mobilising the flexor tendon and fully releasing the volar plate from its proximal attachment. A padded wool and crepe bandage was applied for a week, after which the index and middle fingers were neighbour-strapped and physiotherapy commenced. At four months the patient was discharged with normal power and strength in the hand but a 10 degree block to full flexion of the metacarpophalangeal joint. 


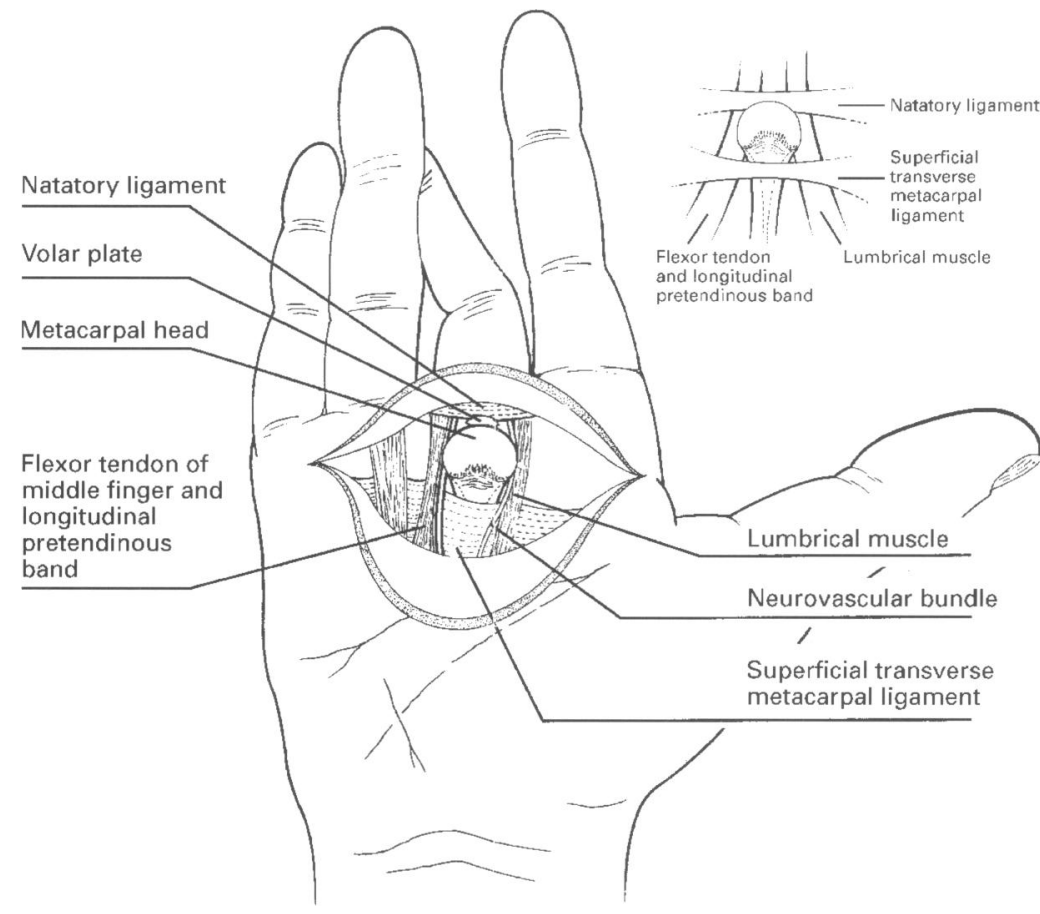

Figure 3 Diagram showing the structures which entrap the metacarpal head as they appear at operation. (Reproduced with permission from Kaplan EB. Dorsal dislocation of the metakarpal phalangeal joint of the index finger. $\mathscr{f}$ Bone foint Surg (Am) 1957;1081-6.)

\section{Learning point}

Inexpert manipulation of a simple dislocation of the metacarpophalangeal joint may convert it to a complex dislocation requiring open reduction

On examination, the metacarpophalangeal joint lies in a position of slight extension and ulnar deviation. The metacarpal head is palpable in the palm and there may be pathognomic puckering of the skin overlying it. ${ }^{1}$ If the joint is hyperextended, the dislocation is likely to be a simple one which can be reduced closed ${ }^{2}$ although inexpert manipulation can convert it to a complex dislocation.

$\mathrm{X}$-Rays confirm the clinical diagnosis and may reveal an associated osteochondral fracture of the metacarpal head or a sesamoid bone in the joint which is pathognomic of volar plate entrapment, as it lies within it. ${ }^{257}$ The volar approach may put the radial neurovascular bundle at risk, ${ }^{2}$ but allows reconstruction of the volar plate. A dorsal approach through skin and extensor tendon permits reduction of the joint but does not allow reconstruction of the volar plate, and there is a theoretical risk of late instability. ${ }^{511}$ If the volar plate is not completely avulsed from the deep transverse metacarpal ligament, a scissoring deformity may result. ${ }^{12}$ If reduction is not delayed, recovery is usually complete, although persisting anaesthesia secondary to digital nerve injury has been described. ${ }^{4581011}$

Complex dislocation of the metacarpophalan geal joint is a relatively rare injury ${ }^{15}$ which usually follows hyperextension of the joint after a fall on the outstretched hand. ${ }^{2}{ }^{9}$ In order of frequency, this occurs most often in the thumb, the index finger, the little finger, the long finger and the ring finger. ${ }^{8}$ Complex dislocation of a central digit is uncommon because the volar plate is supported on both sides by the transverse metacarpal ligament ${ }^{10}$ and so there may be dislocation of the adjacent bordering digit. $^{9}$

\section{Final diagnosis}

Complex dislocation of the metacarpophalangeal joint of the right middle finger.

Keywords: metacarpophalangeal joint; dislocation; finger

Thanks to Mr JF Crossan for permission to report his patient.

1 Kaplan EB. Dorsal dislocation of the metacarpophalangeal joint of the index finger. $\mathcal{F}$ Bone foint Surg Br 57;39A:1081joint

26

Green DP, Terry GC. Complex dislocation of the metacarpophalangeal joint. Correlative pathological anatomy. $\mathcal{f}$ Bone foint Surg Am 1973;55:1480-6.

3 Justis EJ. Fractures, dislocations and ligamentous injuries In: Crenshaw AH, ed. Campbell's Operative orthopaedics, 8th edn. St Louis: Mosby, 1992; pp 3076-8.

4 Nussbaum R, Sadler AH. An isolated, closed, complex dislocation of the metacarpophalangeal joint of the long finger: a unique case. F Hand Surg Am 1986;11:558-61.

5 Becton JL, Christian JD, Jr, Goodwin HN, Jackson JG, 3rd. A simplified technique for treating the complex dislocation of the index metacarpophalangeal joint. $\mathcal{F}$ Bone foint Surg Am 1975;57:698-700.

6 Eglseder WA, Jr, Gens DR, Burgess AR. Multiple ipsilateral dorsal metacarpophalangeal and proximal interphalangeal joint dislocations: a case report. $\mathcal{F}$ Trauma 1995;38:955-7.
7 Baltas D. Complex dislocation of the metacarpophalangeal joint of the index finger with sesamoid entrapment. Injury 995;26:123-5

8 McLaughlin HL. Complex "locked" dislocation of the metacarpophalangeal joints. $\mathcal{F}$ Trauma 1965;5:683-8 locations of the metacarpophalangeal joints of the index long, and ring fingers: a case report. $₹$ Hand Surg Am 1985 10:81-5.

10 al-Qattan MM, Murray KA. An isolated complex dorsal dislocation of the MP joint of the ring finger. $f$ Hand Surg $B r$ 1994;19:171-3.

11 Barry K, McGee H, Curtin J. Complex dislocation of the metacarpo-phalangeal joint of the index finger: a comparison of the surgical approaches. F Hand Surg Br 1988;13: son of 8 .

12 al-Qattan MM, Zuker RM. Scissoring deformity after closed reduction of a dorsal subluxation of the MP joint of the middle finger. $\mathcal{F}$ Hand Surg $B r$ 1994;19:368-70.
9 Hall RF, Jr, Gleason TF, Kasa RF. Simultaneous closed dis- 